\title{
Test Yourself: Question - Lateral Leg Pain
}

\author{
Dana Poletto • Marilyn Bui • Jamie T. Caracciolo
}

Published online: 14 November 2014

(C) ISS 2014

Skeletal Radiology: Test Yourself

Question:

Title: Lateral leg pain.

History: 14 year-old girl presents with proximal lateral leg pain after jumping on a trampoline.

Fig. 1. AP radiograph of the left leg.

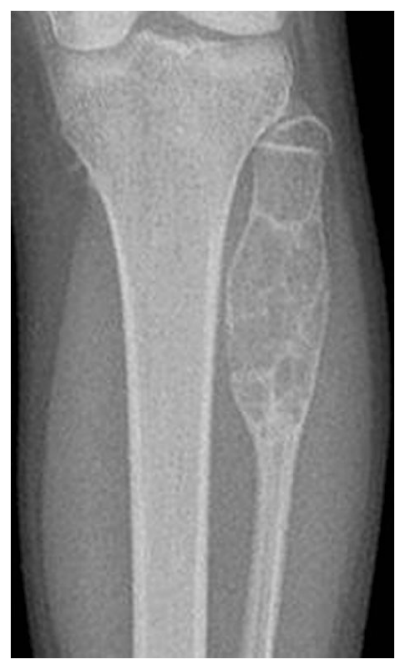

The diagnosis can be found at doi: 10.1007/s00256-014-2050-z

D. Poletto

University of South Florida Morsani College of Medicine, Tampa,

FL, USA

M. Bui

Moffitt Cancer Center, Pathology, Tampa, FL, USA

\section{J. T. Caracciolo ( $₫)$}

Moffitt Cancer Center, Diagnostic Imaging, Tampa, FL, USA

e-mail: jamie.caracciolo@moffitt.org
Fig. 2. a-c. MRI of the left leg - (a) Axial T1-weighted, (b) fat-suppressed T2-weighted, (c) fat-suppressed T1-weighted gadolinium-enhanced imaging.

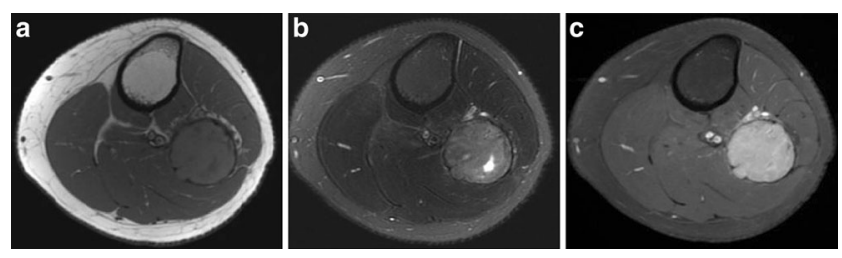

Fig. 3. H\&E stain $200 \mathrm{X}$

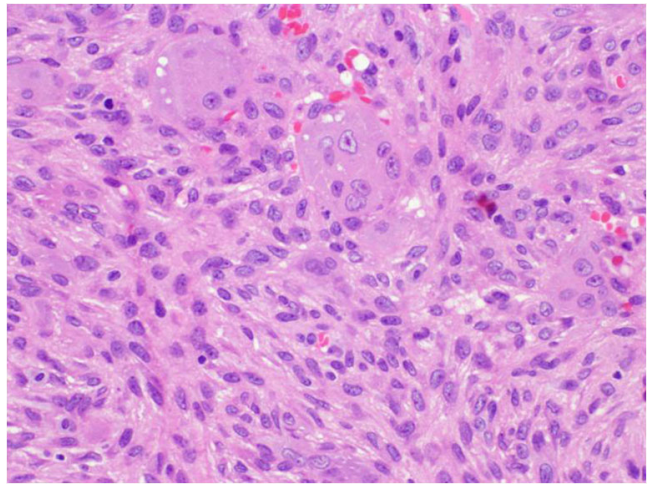

